\title{
Inhibitory effect of 1-tetradecanol on Helicobacter pylori-induced production of interleukin-8 and vascular endothelial growth factor in gastric epithelial cells
}

\author{
GREEN KIM ${ }^{1,2 *}$, JAE-EUN KIM ${ }^{3 *}$, MIN-JUNG KANG ${ }^{1}$, AH-RA JANG $^{1}$, YOUNG RAN KIM ${ }^{4}$, \\ SUNOH KIM $^{5,6}$, KYU-TAE CHANG ${ }^{2}$, JUNG JOO HONG ${ }^{2}$ and JONG-HWAN PARK ${ }^{1}$
}

\author{
${ }^{1}$ Laboratory Animal Medicine, College of Veterinary Medicine, Chonnam National University, Gwangju 61186; \\ ${ }^{2}$ National Primate Research Center, Korea Research Institute of Bioscience and Biotechnology, Cheongju, Chungbuk 28116; \\ ${ }^{3}$ Jeonnam Biopharmaceutical Research Center, Hwasun 58141; ${ }^{4}$ College of Pharmacy and Research Institute of Drug \\ Development, Chonnam National University, Gwangju 61186; ${ }^{5}$ B\&Tech Co., Ltd., R\&D Center, Gwangju 61239; \\ ${ }^{6}$ Division of Food and Nutrition, Chonnam National University, Gwangju 61186, Republic of Korea
}

Received May 25, 2017; Accepted August 10, 2017

DOI: $10.3892 / \mathrm{mmr} .2017 .7793$

\begin{abstract}
Helicobacter pylori (H. pylori) infection activates pro-inflammatory mediators, including interleukin (IL)-8 and vascular endothelial growth factor (VEGF) in gastric epithelial cells. 1-Tetradecanol (1-TD) has been purified from Dendropanax morbifera Leveille; its physiological activities are poorly understood. The present study assessed whether 1-TD has an effect on $H$. pylori-mediated inflammation in AGS gastric epithelial cells. 1-TD reduced IL-8 production by AGS cells in response to $H$. pylori in a significant and dose-dependent manner, as measured by ELISA. Western blot analysis demonstrated that 1-TD also suppressed the activation of nuclear factor- $\kappa \mathrm{B}$, and two mitogen activated protein kinase species (p38 and extracellular signal-regulated kinase 1/2), but not c-Jun N-terminal kinase in $H$.pylori-infected AGS cells. As predicted, VEGF expression and hypoxia inducible factor- $1 \alpha$ stabilization induced by $H$. pylori in AGS cells were inhibited by 1-TD. In addition, 1-TD directly inhibited the growth of $H$. pylori in a dose-dependent manner, as investigated by
\end{abstract}

Correspondence to: Dr Jung Joo Hong, National Primate Research Center, Korea Research Institute of Bioscience and Biotechnology, 30 Yeongudanji-ro, Ochang-eup, Cheongju, Chungbuk 28116, Republic of Korea

E-mail: hong75@kribb.re.kr

Professor Jong-Hwan Park, Laboratory Animal Medicine, College of Veterinary Medicine, Chonnam National University, 77 Yongbong-ro, Buk-gu, Gwangju 61186, Republic of Korea

E-mail: jonpark@jnu.ac.kr

"Contributed equally

Key words: 1-tetradecanol, Helicobacter pylori, IL-8, vascular endothelial growth factor, gastric epithelial cells measuring the optical density. These findings indicated that 1-TD may be a potential preventive or therapeutic agent for $H$. pylori-induced gastric inflammation.

\section{Introduction}

Dendropanax morbifera Leveille (D. morbifera) is a member of the Araliaceae family. It is a subtropical broad-leaved evergreen tree that has been used in traditional medicine for the treatment of headache, infectious disease, skin diseases, and neurological disorders $(1,2)$. The plant contains several components that exhibit various pharmacological effects. One of these is the triterpenoid compound Oleifolioside A, that inhibits nitric oxide (NO) and prostaglandin E2 (PGE2) through the downregulation of nuclear factor $(\mathrm{NF})-\kappa \mathrm{B}$ and mitogen-activated protein kinase (MAPK) signaling in lipopolysaccharide (LPS)-stimulated RAW 264.7 murine macrophages (3), and induces caspase-independent cell death in HeLa human cervical carcinoma cells (4). Ethanol extract of $D$. morbifera induces apoptosis of human leukemia U937 cells through the caspase dependent pathway (1). Anti-cancer activities of methanol extracts have been reported in hepatocarcinoma, colon adenocarcinoma, biliary tract cancer and human osteosarcoma cells (5). Anti-inflammatory responses by $D$. morbifera extracts involve the suppression of $\mathrm{NF}-\kappa \mathrm{B}$ dependent pathways in LPS-stimulated macrophages (6) and microglia (7).

Helicobacter pylori (H. pylori) is a gram negative-bacterium that is commonly located in the stomach of individuals. In some people, $H$. pylori is a pathogen, causing gastric inflammatory diseases including gastritis, peptic ulcer, duodenal ulcer, and even mucosa-associated lymphatic tissue lymphoma $(8,9)$. Production of important inflammatory mediators, such as interleukin (IL)-8 and vascular endothelial growth factor (VEGF), via NF- $\kappa$ B and MAPK signaling in gastric epithelial cells results in gastric inflammation (10) and tumor progression (11).

The present study aimed to investigate whether 1-tetradecanol (1-TD), which was recently isolated from the 
$n$-hexane fraction of $D$. morbifera, has anti-inflammatory activity in $H$. pylori-infected gastric epithelial cells.

\section{Materials and methods}

Preparation of 1-TD. Water extract of Dendropanax morbifera leaves was prepared at $100^{\circ} \mathrm{C}$ for $4 \mathrm{~h}$. The extracted solution was filtered, concentrated with an evaporator under a vacuum, and freeze-dried. The preparation was suspended in water and successively divided with n-hexane, chloroform, ethyl acetate and n-butanol $(3 \times 500 \mathrm{ml})$. Tetradecanol used in this study was isolated from the n-hexane fraction and the purity was confirmed to be $>99 \%$ as described previously (12).

H.pylori strain and culture conditions. H. pylori strain 26695 (American Type Culture Collection, Manassas, VA, USA) was cultured on Brucella broth (BD Biosciences, Franklin Lakes, NJ, USA) containing $10 \%$ fetal bovine serum (FBS; Corning Incorporated, Corning, NY, USA) and antibiotic supplement in a micro-aerobic environment. The bacteria were grown to an optical density at $600 \mathrm{~nm}$ (OD600) of 0.6 measured using an enzyme-linked immunosorbent assay (ELISA) reader (BioTek Instruments, Inc., Winooski, VT, USA), which corresponded to $\sim 10^{9}$ colony-forming units (CFU)/ml and were diluted to the desired concentrations (13).

Cell culture and treatment. The AGS (KCLB; 21739) and MKN45 (KCLB; 80103) human gastric epithelial cell lines were purchased from the Korean Cell Line Bank (Seoul, Korea) and grown in RPMI-1640 medium (Welgene, Inc., Daegu, Korea) supplemented with $10 \%$ FBS and 1X penicillin/streptomycin $(100 \mathrm{U} / \mathrm{ml})$ (Thermo Fisher Scientific, Inc., Waltham, MA, USA) in a humidified atmosphere of 5\% $\mathrm{CO}_{2}$ at $37^{\circ} \mathrm{C}$. Briefly, to determine the secretion of VEGF and IL-8, AGS and MKN45 cells $\left(1 \times 10^{5}\right.$ cells/well in a 48-well plate) were infected with $H$. pylori 26695 at the indicated multiplicity of infection (MOI; 50) in the absence or presence various quantities of 1-TD (30-300 $\mu \mathrm{M}$; Sigma-Aldrich; Merck KGaA, Darmstadt, Germany) for $24 \mathrm{~h}$ in a humidified incubator at $37^{\circ} \mathrm{C}$ in an atmosphere of $5 \% \mathrm{CO}_{2}$. To measure the levels of hypoxia-inducible factor- $1 \alpha$ (HIF-1 $\alpha)$, AGS cells ( $1 \times 10^{6}$ cells/well in a 6 -well plate) were infected with $H$. pylori 26695 at MOI 50 with or without 1-TD $(300 \mu \mathrm{M})$ for $6 \mathrm{~h}$.

Determination of IL-8 and VEGF. The culture supernatants of $H$. pylori-infected AGS and MKN45 cells were collected for ELISA for IL-8 and VEGF. Commercial Duoset ELISA kits (DY208 for IL-8 and DY293B for VEGF; R\&D Systems, Minneapolis, MN, USA) were performed according to the manufacturer's protocol.

MTT assay. An MTT assay was performed to determine the cytotoxicity of 1-TD on gastric epithelial cell lines. The cells ( $1 \times 10^{5}$ cells/well in a 48 -well plate) were treated to different concentrations of 1-TD $(30,100$ and $300 \mu \mathrm{M})$ for $24 \mathrm{~h}$. Each well was incubated with MTT (4 mg/ml; Sigma-Aldrich; Merck $\mathrm{KGaA}$ ) in RPMI-1640 medium (Welgene, Inc.) for $4 \mathrm{~h}$ at $37^{\circ} \mathrm{C}$. After $4 \mathrm{~h}$, the MTT solution was removed and replaced with $200 \mu 1$ of dimethyl sulfoxide (Sigma-Aldrich; Merck KGaA). The plates were agitated for $5 \mathrm{~min}$ to dissolve the formazan crystals. The OD were determined at a wavelength of $570 \mathrm{~nm}$ using an ELISA plate reader (BioTek Instruments, Inc.).

Western blotting. AGS cells were seeded into 35-mm dishes and incubated for 24 h. Cells infected with H. pylori 26695 (MOI 50) were then pre-treated with 1-TD $(300 \mu \mathrm{M})$ for $2 \mathrm{~h}$. After $0,15,30$ or 60 min of treatment, cells were lysed in a buffer containing $1 \%$ Nonidet-P40 supplemented with protease inhibitor (complete Mini EDTA-free; Roche, Mannheim, Germany), phosphatase inhibitor (Phosphatase Inhibitor Cocktail 2; Sigma-Aldrich; Merck KGaA) and $2 \mathrm{mM}$ dithiothreitol. The extracted protein concentration was examined by a Protein Assay kit (500-0006; Bio-Rad Laboratories, Inc., Hercules, CA, USA). Lysates $(30 \mu \mathrm{g})$ were separated by $12 \%$ SDS-PAGE and transferred onto nitrocellulose membranes by electro-blotting. The membranes were blocked with blocking buffer [5\% skimmed milk in PBS-Tween (0.05\% Tween-20)] and incubated at room temperature for $1 \mathrm{~h}$. The membranes were probed with primary antibodies against regular and phosphorylated (p) forms of c-jun N-terminal kinase (JNK; cat. no. 9252; 1:1,000; Cell Signaling Technology, Inc., Beverly, MA, USA), p38 (cat. no. sc 101759; 1:1,000; Santa Cruz Biotechnology, Inc., Dallas, TX, USA), extracellular signal-regulated kinase (ERK; cat. no. sc 7383; 1:1,000; Santa Cruz Biotechnology, Inc.), inhibitor of NF- $\kappa \mathrm{B}$ kinase subunit $\alpha$ (IкB- $\alpha$; 1:1,000; cat. no. 9242S; Cell Signaling Technology, Inc.), p-NF-кB p65 (1:1,000; cat. no. 3033S; Cell Signaling Technology, Inc.) and HIF-1 $\alpha$ (1:1,000, cat. no. 610958; BD Transduction Laboratories; BD Biosciences), followed by an incubation at $4{ }^{\circ} \mathrm{C}$ overnight. A primary antibody against $\beta$-actin (cat. no. sc-130656; 1:1,000; Sigma-Aldrich; Merck KGaA) was used to verify equal loading of protein samples. After immunoblotting with corresponding goat anti-rabbit (cat. no. sc-2301; 1:4,000; Santa Cruz Biotechnology, Inc.) or goat anti-mouse IgG (cat. no. sc-2031; 1:2,000; Santa Cruz Biotechnology, Inc.) secondary antibodies for $2 \mathrm{~h}$ at room temperature, signals were detected with a SuperSignal ${ }^{\mathrm{TM}}$ West Pico Chemiluminescent Substrate (Thermo Fisher Scientific, Inc.). Images of the blots were captured on a CP-BU new film (Agfa Gevaert N.V., Mortsel, Belgium).

Reverse transcription-quantitative polymerase chain reaction (RT-qPCR). Gene expression of VEGF was evaluated by RT-qPCR in AGS cells infected with H. pylori strain 26695 (MOI 50) in the absence or presence of 1-TD (300 $\mu \mathrm{M})$ for $12 \mathrm{~h}$. Total RNA was isolated from cultured cells using the easy-BLUE $^{\mathrm{TM}}$ Total RNA Extraction kit (Intron Biotechnology, Inc., Seongnam, Korea). cDNA was synthesized from $0.1 \mu \mathrm{g}$ RNA using the ReverTra Ace ${ }^{\circledR}$ qPCR RT Master Mix kit (Toyobo Life Science, Osaka, Japan) according to the manufacturer's protocol. qPCR was performed using the Qiagen SYBR Green PCR kit (Qiagen GmbH, Hilden, Germany), according to the manufacturer's protocol. Primers were: VEGF forward, 5'-CCTTGCTGCTCTACCTCCAC-3' and reverse, 5'-TGG TGATGTTGGACTCCTCA-3'; and GAPDH forward, 5'-CGA CTTCAACAGCAACTCCCACTCTTCC-3' and reverse, 5'-TGGGTGGTCCAGGGTTTCTTACTCCTT-3'. qPCR was performed by using a two-step cycle of $95^{\circ} \mathrm{C}$ for $10 \mathrm{sec}$ followed by $58^{\circ} \mathrm{C}$ for $45 \mathrm{sec}$ for 40 cycles in a Roter-GeenQ Real-time PCR system (Qiagen). Gene expression was quantified using the comparative $\mathrm{Ct}$ method, normalizing to GAPDH mRNA (14). 

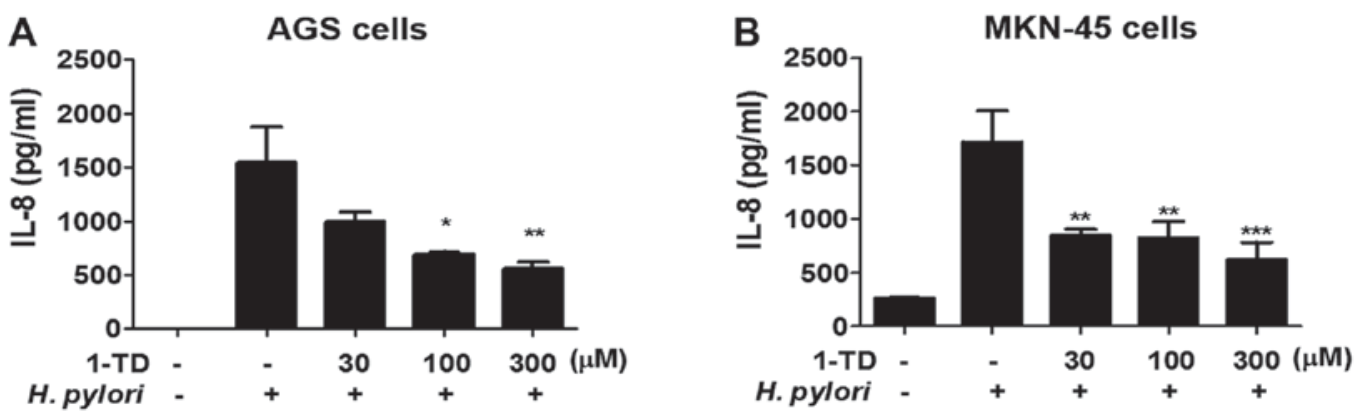

Figure 1. 1-TD inhibits H. pylori-induced IL-8 secretion in gastric epithelial cells. (A) AGS and (B) MKN45 cells were incubated with or without various doses of 1-TD and H. pylori (multiplicity of infection 50) for 24 h; IL-8 secretion in the culture supernatant was measured via ELISA. Data are presented as the mean \pm standard deviation of three separate experiments. 1-TD treated groups were compared with the untreated one and the statistical significance was shown as ${ }^{*} \mathrm{P}<0.05,{ }^{* *} \mathrm{P}<0.01,{ }^{* * *} \mathrm{P}<0.001$. H. pylori, Helicobacter pylori; 1 -TD, 1-tetradecanol; IL-8, interleukin-8.

Anti-bacterial activity. For anti-bacterial testing, $50 \mu \mathrm{l}$ bacterial suspension $\left(1 \times 10^{9} \mathrm{CFU} / \mathrm{ml}\right)$ was added to $2 \mathrm{ml}$ Brucella broth containing various doses of 1-TD. After 6 or $12 \mathrm{~h}$ of incubation at $37^{\circ} \mathrm{C}$ under microaerobic conditions, bacterial growth was determined by measuring the $\mathrm{OD}_{600}$ of the culture broth with an ELISA reader (Epoch; BioTek Instruments, Inc.). The experiment was repeated in triplicate.

Statistical analysis. Data are expressed as the mean \pm standard error. Statistical significances were analyzed by one-way analysis of variance with a Bonferroni post hoc test, and analysis was performed using GraphPad Prism version 5.00 (GraphPad Software, Inc., La Jolla, CA, USA). P<0.01 was considered to indicate a statistically significant difference.

\section{Results}

1-TD suppresses IL-8 production by $H$. pylori-infected gastric epithelial cells. To understand the effects of 1-TD on the $H$. pylori-induced inflammatory immune response in gastric epithelial cells, IL-8 production in AGS cells co-incubated with H.pylori (MOI 50) and 1-TD at concentrations of 30, 100 and $300 \mu \mathrm{M}$ was analyzed. Following an incubation for $24 \mathrm{~h}$, levels of IL-8 significantly decreased in a dose-dependent manner in $H$. pylori-infected AGS cells that were co-treated with 1-TD, compared with $H$. pylori-infected AGS cells that were not co-treated with 1-TD (Fig. 1A). Similar inhibition in another gastric epithelial cell line (MKN45) was also demonstrated (Fig. 1B). In addition, 1-TD was not cytotoxic in either gastric epithelial cell lines at 30,100 and $300 \mu \mathrm{M}$ using MTT assay (data not shown), suggesting that 1-TD is a candidate agent to suppress $H$. pylori-induced inflammation in gastric epithelial cells.

1-TD inhibits the activation of $N F-\kappa B, E R K 1 / 2$ and $p 38$ in $H$. pylori-infected gastric epithelial cells. The activation of $\mathrm{NF}-\kappa \mathrm{B}$ and MAPK signaling is critical for the production of IL-8 in $H$. pylori-infected gastric epithelial cells (11). Therefore, the present study examined the impact of 1-TD treatment on their expression in $H$. pylori-infected AGS cells using western blotting. H. pylori induced decrease of I $\mathrm{B}-\alpha$ at 30 min after infection; however, this process was delayed by 1-TD (Fig. 2). Notably, 1-TD decreased the phosphorylation levels of p65, ERK1/2 and p38, whereas it had no influence

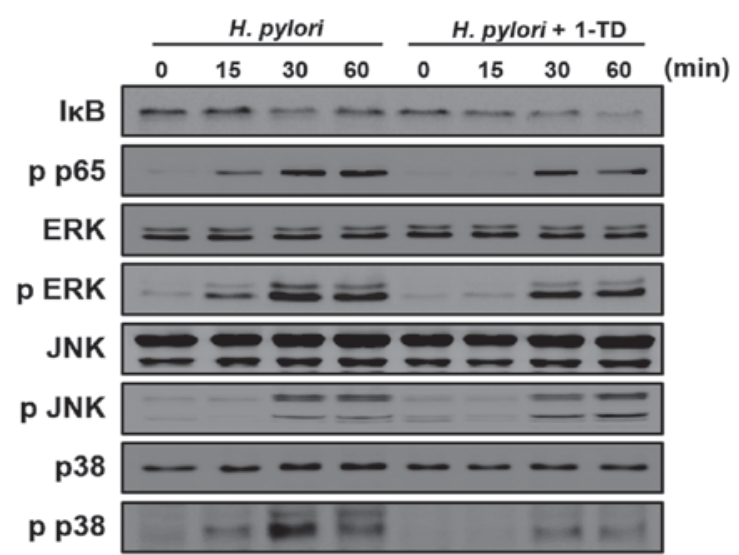

Figure 2. 1-TD inhibits the activation of NF- $\kappa$ B, ERK and p38 induced by H.pylori in infected gastric epithelial cells. AGS cells were pre-treated with $300 \mu \mathrm{M} 1-\mathrm{TD}$ or a solvent control for $6 \mathrm{~h}$ and then infected with $H$. pylori (multiplicity of infection 50). The levels of phosphorylated and total forms of I $\mathrm{B}-\alpha, \mathrm{p} 65$ and mitogen activated protein kinases (p38, ERK1/2 and JNK) were assessed via western blot analysis. ERK1/2, extracellular signal-regulated kinase; JNK, c-Jun N-terminal kinase; p, phosphorylated; H. pylori, Helicobacter pylori; IкB- $\alpha$, inhibitor of NF- $\kappa \mathrm{B}$ kinase subunit $\alpha$; 1-TD, 1-tetradecanol.

on the level of p-JNK (Fig. 2). These results indicated that $1-\mathrm{TD}$ potentially suppresses NF- $\mathrm{KB}$ and MAPK-dependent inflammation in $H$. pylori-infected gastric epithelial cells.

1-TD inhibits $H$. pylori-induced VEGF production in gastric epithelial cells. VEGF production is regulated via $\mathrm{NF}-\kappa \mathrm{B}$, ERK and p38 MAPK in the gastric mucosa $(11,15)$. Therefore, the present study examined the effect of 1-TD on secretion and mRNA expression of VEGF in H.pylori-infected AGS cells. The ELISA results demonstrated that the protein expression level of VEGF was significantly decreased in AGS cells co-treated with $H$. pylori (MOI 50) and 30, 100, and $300 \mu \mathrm{M}$ of $1-\mathrm{TD}$ after $24 \mathrm{~h}$ incubation in a dose-dependent manner (Fig. 3A). Additionally, the mRNA expression of VEGF tended to be lower in H. pylori-infected AGS cells co-treated with 1-TD over time, compared with those in the absence of 1-TD (Fig. 3B). The difference reached statistical significance only at $9 \mathrm{~h}$ (Fig. 3B). These results indicated that 1-TD inhibited protein synthesis and transcription of $H$. pylori-induced VEGF in gastric epithelial cells. 

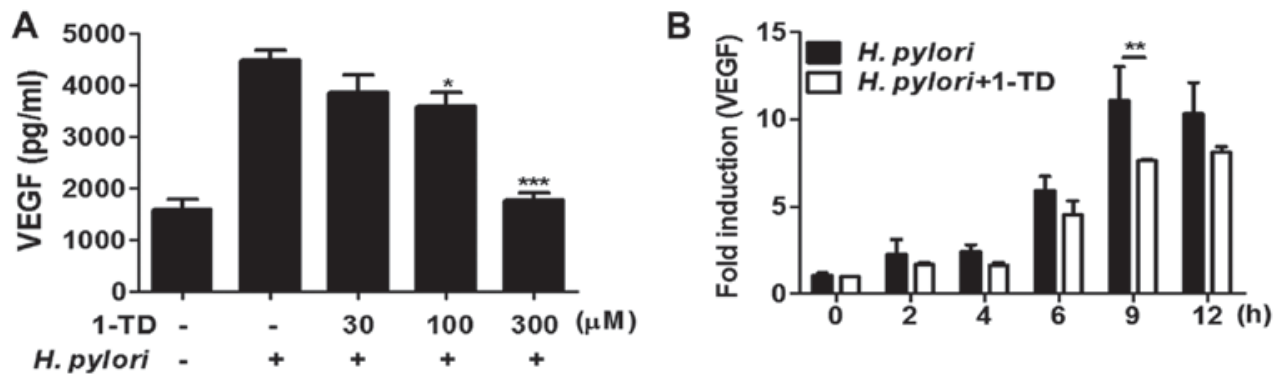

Figure 3. 1-TD inhibits $H$. pylori-induced VEGF secretion in gastric epithelial cells. (A) AGS cells were incubated with or without various concentrations of 1-TD and $H$. pylori at a MOI 50 for $24 \mathrm{~h}$. VEGF secretion in the culture supernatants was measured via ELISA. (B) AGS cells were infected with $H$. pylor $i$ (MOI 50) in the absence or presence of 1-TD $(300 \mu \mathrm{M})$ for indicated times. The expression levels of VEGF mRNA were measured using reverse transcription-quantitative polymerase chain reaction and the fold decrease (arbitrary unit) relative to untreated control cells was calculated. Data are presented as the mean \pm standard deviation of three separate experiments. ${ }^{*} \mathrm{P}<0.05,{ }^{* * *} \mathrm{P}<0.01,{ }^{* * * *} \mathrm{P}<0.001$ vs. H. pylori group. MOI, multiplicity of infection; VEGF, vascular endothelial growth factor; H. pylori, Helicobacter pylori; 1-TD, 1-tetradecanol.

A

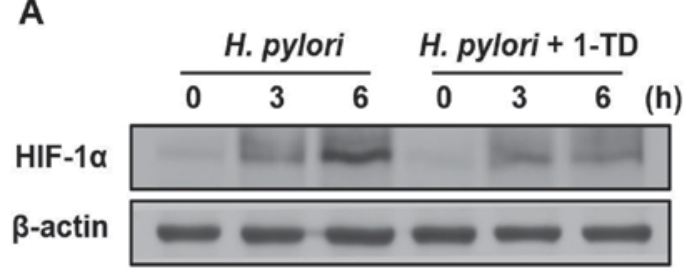

B

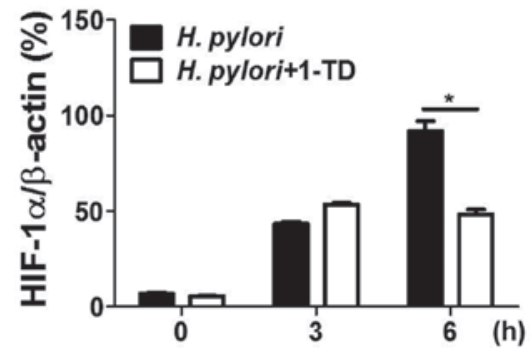

Figure 4. 1-TD inhibits $H$. pylori-nduced HIF-1 $\alpha$ stabilization in gastric epithelial cells. (A) AGS cells were pretreated with or without 300 $\mu \mathrm{M}$ of 1-TD or a solvent control for $6 \mathrm{~h}$ and then cultured with H. pylori (multiplicity of infection 50) for indicated times. The protein levels of HIF-1 $\alpha$ were measured by western blotting. $\beta$-actin was used as a protein loading control for band density normalization. (B) HIF-1 $\alpha$ levels were quantified based on the band density. Data are presented as the mean \pm standard deviation of three separate experiments. 1-TD treated group was compared with the untreated one at each time point $\left(0,3,6\right.$ h). The statistical significance was shown as ${ }^{*} \mathrm{P}<0.05$. H. pylori, Helicobacter pylori; 1 -TD, 1 -tetradecanol; HIF-1 $\alpha$, hypoxia inducible factor-1 $\alpha$.
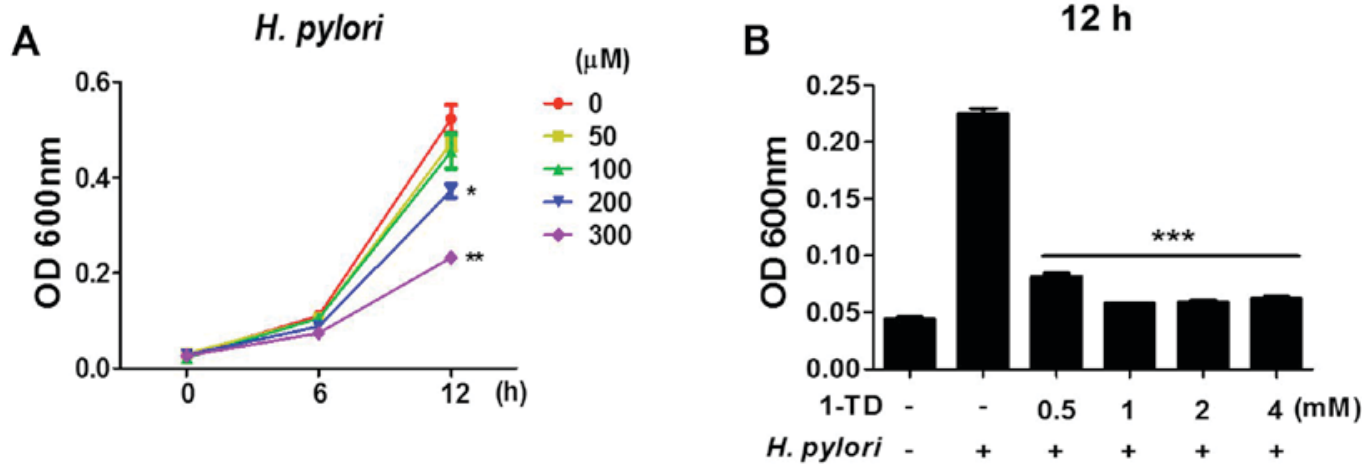

Figure 5. 1-TD exhibits anti-bacterial activity against H.pylori. (A) and (B) growth curves of $H$.pylori, incubated with various doses of 1-TD, in Brucella broth at $37^{\circ} \mathrm{C}$ under microaerobic conditions for (A) 0,6 and $12 \mathrm{~h}$, and (B) $12 \mathrm{~h}$. Data are presented as the mean \pm standard deviation of three separate experiments. ${ }^{*} \mathrm{P}<0.05$ and ${ }^{* *} \mathrm{P}<0.01$ vs. $0 \mu \mathrm{M}$. 1-TD treated groups were compared with the untreated one and the statistical significance was shown as ${ }^{* * *} \mathrm{P}<0.001 . \mathrm{OD}$, optical density; H. pylori, Helicobacter pylori; 1-TD, 1-tetradecanol.

1-TD inhibits $H$. pylori-induced HIF-1a stabilization in gastric epithelial cells. To determine whether 1-TD affects H.pylori-mediated HIF-1 $\alpha$ stabilization in AGS cells, western blot analysis was performed to measure the expression of HIF-1 $\alpha$. 1-TD treatment inhibited H. pylori-induced HIF-1 $\alpha$ protein expression levels at $6 \mathrm{~h}$, compared with that at 0 and $3 \mathrm{~h}$ (Figs. 4A and B), suggesting that 1-TD has an inhibitory effect on $H$. pylori-induced VEGF production through HIF-1 $\alpha$ stabilization.

1-TD affects anti-bacterial activity against $H$. pylori. To assess whether 1-TD has any direct effect on the viability of H. pylori, bacterial growth curves in the presence of 1-TD $(0,50,100,200$ and $300 \mu \mathrm{M})$ for $12 \mathrm{~h}$ were assessed. It was 
demonstrated that there was a dose-dependent reduction in the growth of $H$. pylori at high doses (200 and $300 \mu \mathrm{M})$, while no effect was observed at lower doses (Fig. 5A). To determine a minimal inhibitory concentration (MIC), the bacterial growth was determined in the presence of much higher doses of 1-TD (>500 mM). More than $1 \mathrm{mg}$ of 1-TD completely inhibited the growth of $H$. pylori (Fig. 5B), indicating that the MIC of 1-TD on $H$. pylori is between 0.5 and $1 \mathrm{mg}$. These data suggested a direct inhibitory effect of 1-TD on the growth of H. pylori.

\section{Discussion}

Anti-oxidant, anti-complement, anti-plasmodium and anti-cancer activities have been associated with extracts from the leaves and stems of $D$. morbifera $(5,16,17)$. However, limited data are available about the physiological effects of the compound 1-TD, isolated from the lower stem of D. morbifera. Only a few studies have examined its anti-inflammatory effects on cells such as microglial cells $(6,7)$ and macrophages (3). Furthermore, IL-8, a member of the CXC chemokine family, is involved in inflammatory responses, leukocyte chemotaxis and cancer development $(18,19)$. The high expression of IL-8 is markedly associated with the proliferation, invasion and migration of gastric epithelial cells $(20,21)$. In the case of $H$. pylori infection, IL-8 production is directly increased in gastric epithelial cells $(22,23)$. To the best of our knowledge, the present study was the first to report that 1-TD has potent inhibitory effects against $H$. pylori-induced inflammation. 1-TD significantly inhibited IL-8 production in AGS cells infected with $H$. pylori, suggesting that 1-TD may act as a potential agent to suppress $H$. pylori-induced inflammatory responses involved in IL-8 production.

No cytotoxic effects of 0-300 $\mu \mathrm{M} 1$-TD on H.pylori-infected gastric epithelial cells were evident. In contrast, previous studies have demonstrated that oleifolioside $\mathrm{A}$ and $\mathrm{B}$, ethanol and methanol extracts isolated from $D$. morbifera have cytotoxic effects on human leukemia cells (1), lung carcinoma cells (24), cervical carcinoma cells (4) and hepatocellular carcinoma cells (5). Therefore, the results of the present study suggested that the inhibition of $H$.pylori-induced inflammation in gastric epithelial cells is not due to cell toxicity. Furthermore, 1-TD restricted the growth of $H$.pylori in Brucella broth, indicating direct antibacterial activity, as was previously observed for other long-chain fatty alcohols (25). However, the mechanism through which 1-TD inhibits the bacterial growth is yet to be elucidated.

MAPKs (ERK1/2, p38 and JNK) regulate oxidative stress, gene expression, mitosis, metabolism and apoptosis $(26,27)$. $\mathrm{NF}-\kappa \mathrm{B}$ and MAPK activation are required for transcription of IL- 8 gene induced by $H$. pylori-infected gastric epithelial cells (28). In the present study, pre-treatment with 1-TD inhibited $H$. pylori-induced phosphorylation of p38 MAPK, ERK1/2, and NF- $\mathrm{B}$, suggesting that the inhibition of the levels of IL-8 induced by $H$. pylori was MAPK- and $\mathrm{NF}-\kappa \mathrm{B}$-dependent. In contrast, the phosphorylation of JNK was not affected. A similar observation was previously reported in LPS-stimulated RAW 264.7 macrophages (3). The authors also reported the proinflammatory mediators involved in $\mathrm{NF}-\kappa \mathrm{B}$, p38 MAPK and ERK1/2 signaling by oleifolioside A (3). The potential reduction of these mediators by 1-TD in $H$. pylori-infected epithelial cells was not elucidated in the present study.

During $H$. pylori infection, VEGF can be produced. This is important in vascular remodeling in gastric epithelial cells (29). Our previous study revealed that this production is associated with the activation of NF- $\mathrm{NB}$ and MAPK signaling, as well as HIF-1 $\alpha$ stabilization resulting from the generation of reactive oxygen species induced by $H$. pylori $(30,31)$. In the present study, 1-TD significantly decreased $H$. pylori-induced VEGF production and inhibited HIF-1 $\alpha$ stabilization in AGS cells. These findings suggested that 1-TD may be a novel agent on the inhibition of inflammatory responses involved in angiogenesis in $H$. pylori-infected gastric epithelial cells.

In conclusion, 1-TD effectively inhibited the production of inflammatory mediators (IL- 8 and VEGF) through the inhibition of p38 MAPK, ERK1/2, and NF- $\kappa \mathrm{B}$ signaling in H. pylori-infected gastric epithelial cells. Moreover, 1-TD inhibited the production of VEG and HIF-1 $\alpha$ stabilization induced by $H$. pylori in gastric epithelial cells. Taken together, these data suggested that 1-TD may serve as a novel anti-inflammatory agent for $H$. pylori-infected gastric epithelial cells. Further studies are warranted to evaluate the impact of this anti-inflammatory effect in an in vivo model.

\section{Acknowledgements}

The present study was supported by the Basic Research in Science and Engineering program, funded by the National Research Foundation of Korea (NRF) in the Ministry of Science, ICT, and Future Planning of Korea (MSIP) (grant no. NRF-2015R1A2A2A01002360).

\section{References}

1. Lee JW, Park C, Han MH, Hong SH, Lee TK, Lee SH, Kim GY and Choi YH: Induction of human leukemia U937 cell apoptosis by an ethanol extract of Dendropanax morbifera Lev. through the caspase-dependent pathway. Oncol Rep 30: 1231-1238, 2013.

2. Kim W, Kim DW, Yoo DY, Jung HY, Kim JW, Kim DW, Choi JH, Moon SM, Yoon YS and Hwang IK: Antioxidant effects of Dendropanax morbifera Léveille extract in the hippocampus of mercury-exposed rats. BMC Complement Altern Med 15: 247, 2015.

3. Yu HY, Kim KS, Lee YC, Moon HI and Lee JH: Oleifolioside A, a new active compound, attenuates LPS-stimulated iNOS and COX-2 expression through the downregulation of NF-kappaB and MAPK activities in RAW 264.7 macrophages. Evid Based Complement Alternat Med 2012: 637512, 2012.

4. Yu HY, Jin CY, Kim KS, Lee YC, Park SH, Kim GY, Kim WJ, Moon HI, Choi YH and Lee JH: Oleifolioside A mediates caspase-independent human cervical carcinoma HeLa cell apoptosis involving nuclear relocation of mitochondrial apoptogenic factors AIF and EndoG. J Agric Food Chem 60: 5400-5406, 2012.

5. Hyun TK, Kim MO,Lee H, Kim Y, Kim E and Kim JS: Evaluation of anti-oxidant and anti-cancer properties of Dendropanax morbifera Léveille. Food Chem 141: 1947-1955, 2013.

6. Akram M, Kim KA, Kim ES, Syed AS, Kim CY, Lee JS and Bae ON: Potent anti-inflammatory and analgesic actions of the chloroform extract of Dendropanax morbifera mediated by the Nrf2/HO-1 pathway. Biol Pharm Bull 39: 728-736, 2016.

7. Shim HJ, Park S, Lee JW, Park HJ, Baek SH, Kim EK and Yu SW: Extracts from Dendropanax morbifera leaves have modulatory effects on neuroinflammation in Microglia. Am J Chin Med 44: 119-132, 2016. 
8. Strowski MZ, Cramer T, Schafer G, Schäfer G, Jüttner S, Walduck A, Schipani E, Kemmner W, Wessler S, Wunder C, Weber M, et al: Helicobacter pylori stimulates host vascular endothelial growth factor-A (vegf-A) gene expression via MEK/ERK-dependent activation of Sp1 and Sp3. FASEB J 18: 218-220, 2004

9. Brown LM: Helicobacter pylori: Epidemiology and routes of transmission. Epidemiol Rev 22: 283-297, 2000.

10. Sue S, Shibata W and Maeda S: Helicobacter pylori-Induced signaling pathways contribute to intestinal metaplasia and gastric carcinogenesis. Biomed Res Int 2015: 737621, 2015.

11. Kim G, Kim TH, Kang MJ, Choi JA, Pack DY, Lee IR, Kim MG, Han SS, Kim BY, Oh SM, et al: Inhibitory effect of withaferin A on Helicobacter pylori induced IL8 production and NF- $\kappa \mathrm{B}$ activation in gastric epithelial cells. Mol Med Rep 13: 967-972, 2016

12. Lee SY, Choi EJ, Bae DH, Lee DW and Kim SO: Effects of 1 -tetradecanol and $\beta$-sitosterol isolated from Dendropanax morbifera Lev. on skin whitening, moisturizing and preventing hair loss. J Soc Cosmet Sc. Korea 41: 73-83, 2015.

13. Kao JY, Zhang M, Miller MJ, Mills JC, Wang B, Liu M, Eaton KA, Zou W, Berndt BE, Cole TS, et al: Helicobacter pylori immune escape is mediated by dendritic cell-induced Treg skewing and Th17 suppression in mice. Gastroenterology 138 : 1046-1054, 2010.

14. Livak KJ and Schmittgen TD: Analysis of relative gene expression data using real-time quantitative PCR and the 2(-Delta Delta C(T)) method. Methods 25: 402-408, 2001.

15. Kang MJ, Song EJ, Kim BY, Kim DJ and Park JH: Helicobacter pylori induces vascular endothelial growth factor production in gastric epithelial cells through hypoxia-inducible factor-1 $\alpha$-dependent pathway. Helicobacter 19: 476-483, 2014.

16. Chung IM, Kim MY, Park SD, Park WH and Moon HI: In vitro evaluation of the antiplasmodial activity of Dendropanax morbifera against chloroquine-sensitive strains of Plasmodium falciparum. Phytother Res 23: 1634-1637, 2009.

17. Park BY, Min BS, Oh SR, Kim JH, Kim TJ, Kim DH, Bae KH and Lee HK: Isolation and anticomplement activity of compounds from Dendropanax morbifera. J Ethnopharmacol 90: 403-408, 2004.

18. Liu CJ, Kuo FC, Wang CL, Kuo CH, Wang SS, Chen CY, Huang YB, Cheng KH, Yokoyama KK, Chen CL, et al: Suppression of IL-8-Src signalling axis by $17 \beta$-estradiol inhibits human mesenchymal stem cells-mediated gastric cancer invasion. J Cell Mol Med 20: 962-972, 2016.

19. Shi J, Li YJ, Yan B and Wei PK: Interleukin-8: A potent promoter of human lymphatic endothelial cell growth in gastric cancer. Oncol Rep 33: 2703-2710, 2015.
20. Raman D, Baugher PJ, Thu YM and Richmond A: Role of chemokines in tumor growth. Cancer Lett 256: 137-165, 2007.

21. Xie K: Interleukin- 8 and human cancer biology. Cytokine Growth Factor Rev 12: 375-391, 2001.

22. Crabtree JE, Farmery SM, Lindley IJ, Figura N, Peichl P and Tompkins DS: CagA/cytotoxic strains of Helicobacter pylori and interleukin-8 in gastric epithelial cell lines. J Clin Pathol 47: 945-950, 1994

23. Sharma SA, Tummuru MK, Miller GG and Blaser MJ: Interleukin-8 response of gastric epithelial cell lines to Helicobacter pylori stimulation in vitro. Infect Immun 63: 1681-1687, 1995.

24. Jin CY, Yu HY, Park C, Han MH, Hong SH, Kim KS, Lee YC, Chang YC, Cheong J, Moon SK, et al: Oleifolioside B-mediated autophagy promotes apoptosis in A549 human non-small cell lung cancer cells. Int J Oncol 43: 1943-1950, 2013.

25. Togashi N, Shiraishi A, Nishizaka M, Matsuoka K, Endo K, Hamashima $\mathrm{H}$ and Inoue $\mathrm{Y}$ : Antibacterial activity of long-chain fatty alcohols against Staphylococcus aureus. Molecules 12: 139-148, 2007.

26. Ki YW, Park JH, Lee JE, Shin IC and Koh HC: JNK and p38 MAPK regulate oxidative stress and the inflammatory response in chlorpyrifos-induced apoptosis. Toxicol Lett 218: 235-245, 2013.

27. Johnson GL and Lapadat R: Mitogen-activated protein kinase pathways mediated by ERK, JNK, and p38 protein kinases. Science 298: 1911-1912, 2002.

28. Lee KE, Khoi PN, Xia Y, Park JS, Joo YE, Kim KK, Choi SY and Jung YD: Helicobacter pylori and interleukin- 8 in gastric cancer. World J Gastroenterol 19: 8192-8202, 2013.

29. Shibuya M: Vascular endothelial growth factor and its receptor system: Physiological functions in angiogenesis and pathological roles in various diseases. J Biochem 153: 13-19, 2013.

30. Park JH, Kim TY, Jong HS, Kim TY, Chun YS, Park JW, Lee CT, Jung HC, Kim NK and Bang YJ: Gastric epithelial reactive oxygen species prevent normoxic degradation of hypoxia-inducible factor-1alpha in gastric cancer cells. Clin Cancer Res 9: 433-440, 2003.

31. Wu CY, Wang CJ, Tseng CC, Chen HP, Wu MS, Lin JT, Inoue H and Chen GH: Helicobacter pylori promote gastric cancer cells invasion through a NF-kappaB and COX-2-mediated pathway. World J Gastroenterol 11: 3197-3203, 2005. 